\title{
Histological and histometric study of the small intestine in Stara Zagora white turkey in age aspect
}

\author{
David Yovchev ${ }^{1}$ \\ ${ }^{1}$ Department of Anatomy, Histology and Embryology, Faculty of Veterinary Medicine, Trakia University, Stara Zagora/BULGARIA
}

Key Words:
histology
histometry
small intestine
Stara Zagora white turkey


Received $\quad: 03.08 .2021$
$\begin{aligned} & \text { Accepted } \\ & \text { Published Online }: 31.12 .2021 \\ & \text { Article Code }: 978101\end{aligned}$

Correspondence:

D. YOVCHEV

(vetjovchev@yahoo.com)

ORCID:

D. YOVCHEV : 0000-0003-4357-0858

\begin{abstract}
Thirty clinically healthy Stara Zagora white turkeys (15 females and 15 males) were used for the study. Eighteen tissue samples (six from the middle of each segment of the small intestine) of the appropriate age group were used to prepare permanent histological specimens. The histological sections were stained by Masson - Goldner method. The small intestine of the Stara Zagora white turkey was composed of four tissue layers: tunica mucosa, tunica submucosa, tunica muscularis and tunica serosa. Tunica mucosa had lamina epithelialis, lamina propria and lamina muscularis mucosae. The layers of the mucosa formed well-defined intestinal villi - villi intestinales. Lamina epithelialis was composed of highly differentiated simple columnar epithelium. Tunica mucosa in the three segments of the small intestine had clearly distinct tubular glands - gll. Intestinales. The histometric results showed that the growth of the mucosal structures and the mucosa was more intense in the first twenty-eight days, compared to the growth of the other layers of the intestinal wall. The most intense was the increase in the height and area of the intestinal villi. The height of the intestinal villi varied most markedly during the first twenty-eight days of the duodenal examination, while the area of the villi increased most in the jejunum, followed by the ileum and duodenum. The height of the intestinal epithelium increased most intensively 2.3 times in the jejunum mucosa. The thickness of the jejunal mucosa increased the most during this period, compared to the mucosa of the duodenum ileum.
\end{abstract}

\section{INTRODUCTION}

Morphometric studies of internal organs in Anseriformes found a variable change in the length of the tubal organsesophagus and intestine $(1,2,3)$.

Objective data regarding the development of the intestine in quails, ducks, geese and guinea fowl were obtained using statistical methods $(4,5,6,7)$.

The length of the body in marine ducks and the volume of the organs that construct their digestive system are directly proportional to the food components and the type of diet (8).

All digestive organs of the duck, with the exception of the esophagus, reach peak growth levels earlier than the body weight of the birds (9).

The microscopic anatomy of the digestive system in poultry is governed by certain principles. The tubular digestive organs have highly differentiated epithelial cells on their inner surface, surrounded by loose fibrous connective and muscle tissue. This is the so-called mucosal layer $(10,11)$.

The basic structure of the ileum in the domestic turkey does not differ from that of the duodenum and the jejunum. The villi in the ileum are shorter and few in number, compared to the same structures in the duodenum and jejunum. The goblet cells are the most numerous (12).
On histological study is found that the small intestine of the Bronze Turkey has four layers: tunica mucosa, tunica submucosa, tunica muscularis and tunica serosa. Tunica mucosa has lamina epithelialis, lamina propria and lamina muscularis mucosae. Intestinal villi are mucous formations on the luminal surface of the intestinal wall. Lamina epithelialis is composed of a single layer of columnar epithelium. On the first day after hatching, the epithelial cells are oval in shape, which later acquire a columnar shape with pronounced morphological polarity. The height and width of the intestinal villi increase with age. These changes are observed in the three segments of the small intestine (duodenum, jejunum and ileum). The height of the intestinal villi in the jejunum and ileum is higher than in the duodenum. At the same time, the increase in the width and height of the villi corresponds to the increase in the absorption surface. The values of the area of the villi are directly proportional to the changes in their width and height. The intensity of growth of intestinal crypts in the first 90 days has similar trends in the duodenum, and the fastest growth rates have been found for crypts in the ileum. The ratio of the height of the intestinal villi to the depth of the crypts increases in the first 28 days for all segments of the small intestine (12)

The height of the intestinal villi in the duodenum and jejunum in the bronze turkey throughout the study period increases 7.8 times, while the same indicator in the ileum 6.4 times. During the period from the 1 st to the 35 th day the fastest growth rate of the width of the intestinal villi was 
found in the duodenum - 2.6 times, and with the weakest rate the same indicator was reported in the ileum - 1.9 times. The obtained data for the area of the villi are directly proportional to the changes in the width and height of the studied intestinal structures. The values concerning the depth of the intestinal crypts in the duodenum, jejunum and ileum increase more intensively in the first 90 days after hatching. The fastest growth rates are characteristic of the crypts in the ileum (12).

\section{MATERIAL and METHODS}

Thirty clinically healthy Stara Zagora white turkeys (15 females and 15 males) were used for the study.

Eighteen tissue samples (six from the middle of each segment of the small intestine) of the appropriate age group were used to prepare permanent histological specimens. The resulting tissue samples were fixed in $8 \%$ aqueous formaldehyde solution (Merck KGaA, Darmastadt, Germany). After fixation, they were washed under running water, dehydrated in ascending ethanol series, clarified in xylene and embedded in paraffin. Using a YD-335A rotary microtome (J. Y. M. A. Ltd., China), sections 5 to $7 \mu \mathrm{m}$ thick were made and stained by Masson Goldner method. Histological samples were observed with a Leica DM 1000 light microscope.

Structures from five histological sections obtained from each tissue sample were selected and measured. Micrometric measurements were processed using LAS V4.10 software for Leica DM 1000 light microscope.

The one-way ANOVA method was chosen for statistical processing of the obtained data, and for this purpose we used StatView v. 4.53 for Windows (Abacus Concepts, Inc). Statistically significant differences between the mean values of the age groups were determined at $\mathrm{P}<0.05$ (13).

The results obtained were interpreted in accordance with the histological terminology (14).

The requirements of the normative regulations were observed - Ordinance No 36 of March 23, 2006, promulgated. in SG, No 35 of 28. 04. 2006 and Ordinance No 8, promulgated, SG, iss. 4 of 16. 01. 2004, amended and add., No. 19 of 13 March 2015. The experiments were performed in strict accordance with the rules of the ethics committee at Trakia University, Stara Zagora.

\section{RESULTS}

The small intestine of the Stara Zagora white turkey was composed of four tissue layers: tunica mucosa, tunica submucosa, tunica muscularis and tunica serosa. Tunica mucosa had lamina epithelialis, lamina propria and lamina muscularis mucosae. The lavers of the mucosa formed well-defined intestinal villi villi intestinales. Lamina epithelialis was composed of highly differentiated simple columnar epithelium. Tunica mucosa in the three segments of the small intestine had clearly distinct tubular glands - gll. intestinales (Liberkyun glands) (Figure 1, Figure 2 and Figure 3).

Analysis of the histometric results showed that the growth of the mucosal structures and the mucosa as a whole was more

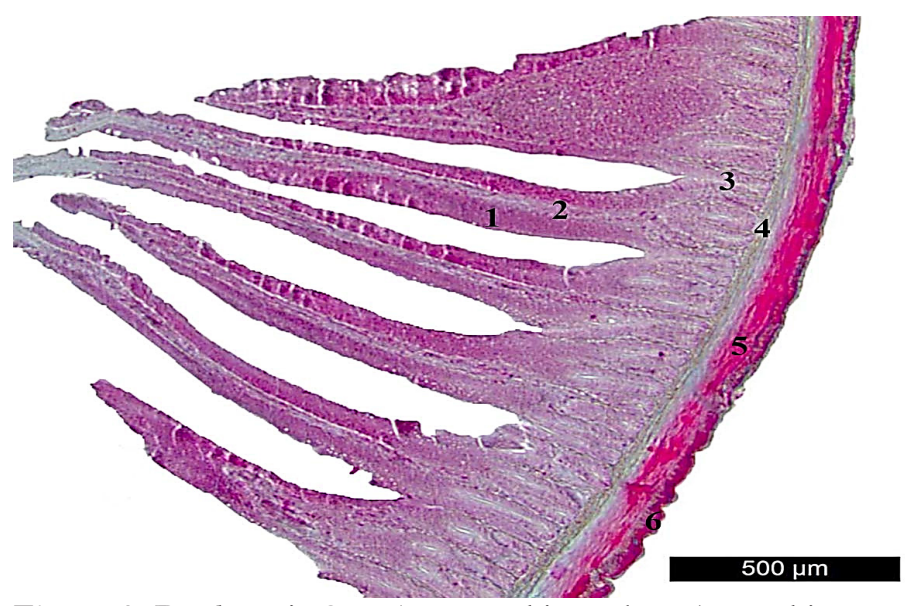

Figure 1. Duodenum in Stara Zagora white turkeys (age - thirtyfive days). (1) lamina epithelialis mucosae; (2) lamina propria mucosae; (3) intestinal crypt; (4) tunica submucosa; (5) tunica muscularis - internal sublayer; (6) tunica muscularis - external sublayer. Masson's trichrome stain. Line $=500 \mu \mathrm{m}$.

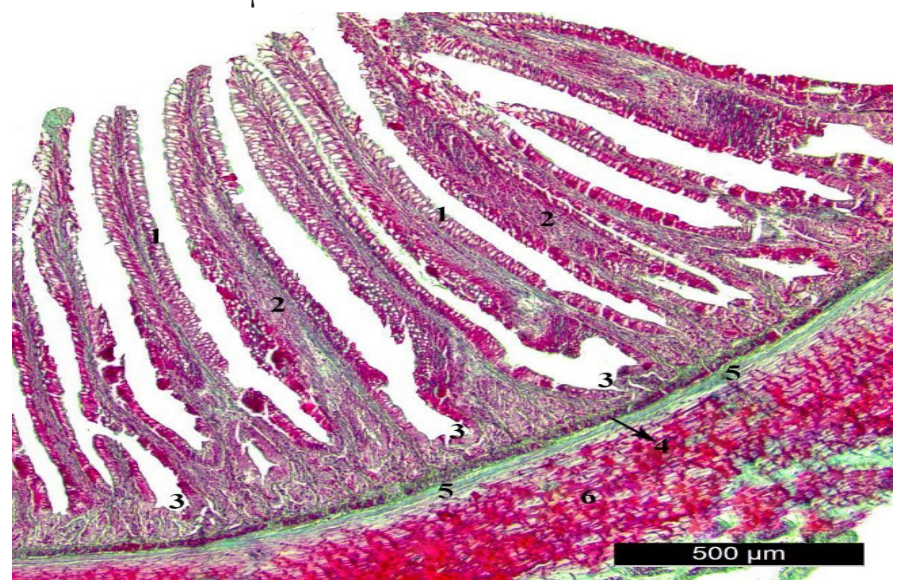

Figure 2. Jejunum in Stara Zagora white turkeys (age - thirty-five days). (1) lamina epithelialis mucosae; (2) lamina propria mucosae; (3) intestinal crypt; (4) lamina muscularis mucosae; (5) tunica submucosa; (6) tunica muscularis. Masson's trichrome stain. Line $=500 \mu \mathrm{m}$.

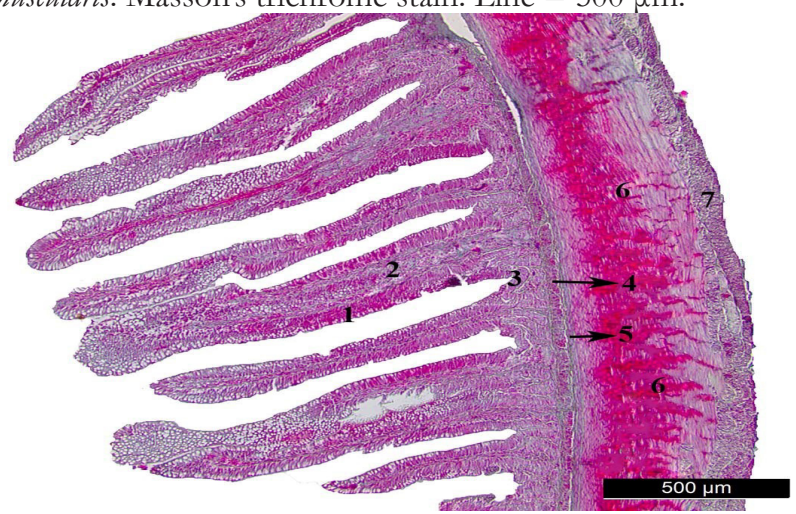

Figure 3. Ileum in Stara Zagora white turkeys (age - thirty-five days). (1) lamina epithelialis mucosae; (2) lamina propria mucosae; (3) intestinal crypt; (4) lamina muscularis mucosae; (5) tunica submucosa; (6) tunica muscularis - internal sublayer; (7) tunica muscularis - external sublayer. Masson's trichrome stain. Line $=500 \mu \mathrm{m}$.

intense in the first twenty-eight days, compared to the growth of the other layers of the intestinal wall. The most intense was the increase in the height and area of the intestinal villi, and the weaker was the increase in the depth of the crypts and the height of the mucosal epithelium. The height of the intestinal villi varied most markedly during the first twenty-eight days of the duodenal examination, while the area of the villi increased 
Table 1. Histometric parameters of some duodenal structures in Stara Zagora white turkey (mean \pm SEM)

\begin{tabular}{cccccccc}
\hline Duodenal structures & \multicolumn{7}{c}{ Age (days) } \\
\cline { 2 - 7 } & 1 & 7 & 14 & 28 & 35 & 49 & 56 \\
\hline Height of villus & $186.05 \pm$ & $285.25 \pm$ & $356.14 \pm$ & $752.36 \pm$ & $1045.25 \pm$ & $1210.25 \pm$ & $1235.89 \pm$ \\
& $9.04^{\mathrm{a}}$ & $11.48^{\mathrm{b}}$ & $10.28^{\mathrm{a}}$ & $15.85^{\mathrm{a}}$ & $28.36^{\mathrm{a}}$ & $85.69^{\mathrm{a}}$ & $69.58^{\mathrm{a}}$ \\
Depth of crypts & $36.89 \pm$ & $76.18 \pm$ & $82.35 \pm$ & $125.5 \pm$ & $185.65 \pm$ & $288.36 \pm$ & $304.58 \pm$ \\
& $5.14^{\mathrm{b}}$ & $6.16^{\mathrm{a}}$ & $10.25^{\mathrm{b}}$ & $12.33^{\mathrm{b}}$ & $9.36^{\mathrm{b}}$ & $12.36^{\mathrm{b}}$ & $26.36^{\mathrm{c}}$ \\
Height of epithelium & $15.17 \pm$ & $20.58 \pm$ & $22.35 \pm$ & $25.36 \pm$ & $27.85 \pm$ & $32.25 \pm$ & $35.96 \pm$ \\
& $1.17^{\mathrm{c}}$ & $0.96^{\mathrm{c}}$ & $1.25^{\mathrm{c}}$ & $2.25^{\mathrm{a}}$ & $2.96^{\mathrm{c}}$ & $2.35^{\mathrm{c}}$ & $2.48^{\mathrm{c}}$ \\
Villus area & $407.63 \pm$ & $679.85 \pm$ & $845.58 \pm$ & $1432.25 \pm$ & $2218.36 \pm$ & $2395.65 \pm$ & $2578.36 \pm$ \\
Tunica mucosae & $65.36^{\mathrm{a}}$ & $79.36^{\mathrm{a}}$ & $72.25^{\mathrm{a}}$ & $125.58^{\mathrm{c}}$ & $124.85^{\mathrm{c}}$ & $112.32^{\mathrm{c}}$ & $152.28^{\mathrm{a}}$ \\
& $201.25 \pm$ & $365.85 \pm$ & $437.48 \pm$ & $895.62 \pm$ & $1014.35 \pm$ & $1420.25 \pm$ & $1432.88 \pm$ \\
Tunica submucosae & $24.58^{\mathrm{b}}$ & $26.58^{\mathrm{b}}$ & $19.85^{\mathrm{c}}$ & $24.45^{\mathrm{a}}$ & $85.25^{\mathrm{a}}$ & $105.25^{\mathrm{a}}$ & $110.25^{\mathrm{c}}$ \\
Tunica muscularis - & $6.25 \pm$ & $8.14 \pm$ & $17.85 \pm$ & $19.25 \pm$ & $21.45 \pm$ & $23.45 \pm$ & $25.85 \pm$ \\
internal sublayer & $2.56^{\mathrm{a}}$ & $3.25^{\mathrm{c}}$ & $2.89^{\mathrm{a}}$ & $5.65^{\mathrm{c}}$ & $7.89^{\mathrm{c}}$ & $8.16^{\mathrm{c}}$ & $6.96^{\mathrm{c}}$ \\
Tunica muscularis - & $21.25 \pm$ & $28.92 \pm$ & $38.25 \pm$ & $40.02^{\mathrm{c}} \pm$ & $52.24 \pm$ & $63.28 \pm$ & $60.91 \pm$ \\
external sublayer & $0.55^{\mathrm{c}}$ & $1.02^{\mathrm{a}}$ & $1.25^{\mathrm{c}}$ & $2.15^{\mathrm{c}}$ & $2.84^{\mathrm{c}}$ & $3.02^{\mathrm{a}}$ & $3.92^{\mathrm{b}}$ \\
\hline
\end{tabular}

Table 2. Histometric parameters of some jejunal structures in Stara Zagora white turkey (mean \pm SEM)

\begin{tabular}{cccccccc}
\hline Jejunal structures & \multicolumn{7}{c}{ Age (days) } \\
\cline { 2 - 7 } & 1 & 7 & 14 & 28 & 35 & 49 & 56 \\
\hline Height of villus & $118.58 \pm$ & 225.58 & $318.48 \pm$ & $450.25 \pm$ & $478.58 \pm$ & $560.23 \pm$ & $985.25 \pm$ \\
& $10.25^{\mathrm{a}}$ & $9.85^{\mathrm{b}}$ & $10.23^{\mathrm{a}}$ & $8.56^{\mathrm{b}}$ & $12.35^{\mathrm{a}}$ & $48.25^{\mathrm{b}}$ & $96.36^{\mathrm{a}}$ \\
Depth of crypts & $20.34 \pm$ & $38.58 \pm$ & $63.85 \pm$ & $90.25 \pm$ & $125.85 \pm$ & $156.89 \pm$ & $185.95 \pm$ \\
& $0.24^{\mathrm{b}}$ & $0.38^{\mathrm{a}}$ & $0.98^{\mathrm{b}}$ & $1.25^{\mathrm{a}}$ & $2.14^{\mathrm{b}}$ & $4.17^{\mathrm{a}}$ & $6.17^{\mathrm{b}}$ \\
Height of epithelium & $10.28 \pm$ & $16.58 \pm$ & $20.58 \pm$ & $23.65 \pm$ & $25.14 \pm$ & $30.76 \pm$ & $32.25 \pm$ \\
\cline { 2 - 7 } & $0.24^{\mathrm{a}}$ & $0.58^{\mathrm{b}}$ & $0.75^{\mathrm{a}}$ & $1.12^{\mathrm{b}}$ & $1.52^{\mathrm{a}}$ & $2.02^{\mathrm{b}}$ & $1.65^{\mathrm{a}}$ \\
Villus area & $3568.58 \pm$ & $14587 \pm$ & $16854.35 \pm$ & $28547.58 \pm$ & $36958.59 \pm$ & $47158.25 \pm$ & $50284.24 \pm$ \\
Tunica mucosae & $125.85^{\mathrm{b}}$ & $185.25^{\mathrm{a}}$ & $198.58^{\mathrm{b}}$ & $214.74^{\mathrm{a}}$ & $617.84^{\mathrm{b}}$ & $624.25^{\mathrm{a}}$ & $785.59^{\mathrm{b}}$ \\
Tunica submucosae & $131.25 \pm$ & $299.65 \pm$ & $396.58 \pm$ & $614.28 \pm$ & $728.58 \pm$ & $1068.98 \pm$ & $1289.65 \pm$ \\
Tunica muscularis - & $5.65^{\mathrm{c}}$ & $4.16^{\mathrm{c}}$ & $4.58^{\mathrm{c}}$ & $9.18^{\mathrm{b}}$ & $8.97^{\mathrm{c}}$ & $25.85^{\mathrm{b}}$ & $35.69^{\mathrm{c}}$ \\
internal sublayer & $1.24^{\mathrm{c}}$ & $2.05^{\mathrm{a}}$ & $2.58^{\mathrm{b}}$ & $4.12^{\mathrm{a}}$ & $5.15^{\mathrm{b}}$ & $6.18^{\mathrm{a}}$ & $7.14^{\mathrm{b}}$
\end{tabular}

most in the jejunum, followed by the ileum and duodenum. The height of the intestinal epithelium increased most intensively 2.3 times in the jejunum mucosa. The thickness of the jejunal mucosa increased the most during this period, compared to the mucosa of the duodenum ileum. Tunica submucosa and the sublayers of tunica muscularis grew at almost uniform rates in 
Table 3. Histometric parameters of some ileal structures in Stara Zagora white turkey (mean \pm SEM)

\begin{tabular}{|c|c|c|c|c|c|c|c|}
\hline \multirow[t]{2}{*}{ Ileal structures } & \multicolumn{5}{|c|}{ Age (days) } & \multirow[b]{2}{*}{49} & \multirow[b]{2}{*}{56} \\
\hline & 1 & 7 & 14 & 28 & 35 & & \\
\hline \multirow{2}{*}{ Height of villus } & $145.85 \pm$ & $298.35 \pm$ & $458.95 \pm$ & $532.25 \pm$ & $678.59 \pm$ & $758.25 \pm$ & $835.69 \pm$ \\
\hline & $8.56^{\mathrm{a}}$ & $7.16^{\mathrm{b}}$ & $12.15^{a}$ & $10.85^{a}$ & $13.45^{b}$ & $16.78^{c}$ & $20.21^{a}$ \\
\hline \multirow{2}{*}{ Depth of crypts } & $41.42 \pm$ & $78.56 \pm$ & $85.25 \pm$ & $158.95 \pm$ & $167.84 \pm$ & $178.95 \pm$ & $195.58 \pm$ \\
\hline & $2.16^{\mathrm{b}}$ & $3.15^{\mathrm{a}}$ & $4.58^{\mathrm{b}}$ & $9.50^{\mathrm{b}}$ & $12.58^{a}$ & $15.58^{b}$ & $12.25^{\mathrm{b}}$ \\
\hline \multirow{2}{*}{ Height of epithelium } & $12.45 \pm$ & $14.28 \pm$ & $15.23 \pm$ & $17.34 \pm$ & $22.58 \pm$ & $27.48 \pm$ & $32.58 \pm$ \\
\hline & $0.25^{\mathrm{c}}$ & $0.34^{\mathrm{a}}$ & $0.22^{\mathrm{a}}$ & $0.58^{\mathrm{c}}$ & $0.98^{\mathrm{c}}$ & $1.34^{\mathrm{a}}$ & $1.28^{\mathrm{c}}$ \\
\hline \multirow{2}{*}{ Villus area } & $4560.25 \pm$ & $14582.36 \pm$ & $28352 \pm$ & $34568 \pm$ & $45895.35 \pm$ & $56897.23 \pm$ & $69854.56 \pm$ \\
\hline & $125.87^{a}$ & $156.78^{b}$ & $168.98^{c}$ & $212.58^{a}$ & $198.89^{a}$ & $159.23^{c}$ & $256.34^{\mathrm{a}}$ \\
\hline \multirow{2}{*}{ Tunica mucosae } & $235.35 \pm$ & $386.65 \pm$ & $612.22 \pm$ & $784.58 \pm$ & $854.56 \pm$ & $925.58 \pm$ & $1041.25 \pm$ \\
\hline & $5.89^{\mathrm{b}}$ & $7.89^{a}$ & $12.15^{\mathrm{a}}$ & $19.96^{\mathrm{a}}$ & $29.59^{c}$ & $28.85^{a}$ & $26.62^{b}$ \\
\hline \multirow{2}{*}{ Tunica submucosae } & $8.25 \pm$ & $12.59 \pm$ & $21.58 \pm$ & $28.65 \pm$ & $45.25 \pm$ & $51.25 \pm$ & $69.58 \pm$ \\
\hline & $0.55^{\mathrm{c}}$ & $0.69^{\mathrm{c}}$ & $0.95^{\mathrm{c}}$ & $1.12^{\mathrm{b}}$ & $5.65^{b}$ & $4.28^{\mathrm{b}}$ & $5.16^{\mathrm{c}}$ \\
\hline Tunica muscularis - & $52.28 \pm$ & $56.89 \pm$ & $86.32 \pm$ & $121.23 \pm$ & $182.56 \pm$ & $195.69 \pm$ & $280.56 \pm$ \\
\hline internal sublayer & $6.15^{b}$ & $4.13^{a}$ & $5.12^{\mathrm{a}}$ & $8.16^{\mathrm{c}}$ & $14.25^{\mathrm{a}}$ & $15.85^{\mathrm{a}}$ & $24.58^{a}$ \\
\hline Tunica muscularis - & $16.58 \pm$ & $18.59 \pm$ & $34.58 \pm$ & $54.25 \pm$ & $57.89 \pm$ & $62.23 \pm$ & $99.65 \pm$ \\
\hline external sublayer & $1.21^{\mathrm{a}}$ & $0.58^{\mathrm{c}}$ & $2.89^{c}$ & $2.58^{\mathrm{a}}$ & $9.16^{\mathrm{c}}$ & $5.98^{\mathrm{c}}$ & $12.19^{c}$ \\
\hline
\end{tabular}

the three segments of the small intestine, except for the outer sublayer of tunica muscularis of the ileum, where the thickness doubled (Table1, Table 2 and Table 3).

\section{DISCUSSION}

The data presented by us about the micrometric changes in the layers and mucous structures of the small intestine in the Stara Zagora White Turkey complement the thesis of some authors $(1,2)$ for the chages of the organs from the digestive tract in age aspect. In our opinion, the growth of the mucosal structures and the mucosa was more intense during the first twenty-eight days, compared to the growth of the other layers of the intestinal wall.

The results, which expressed the age-related changes in the studied structures from the histological sections, were statistically processed for completeness. Like other studies (4, $5,6,7)$, we assume that such changes are reported as objective after statistical processing.

Based on the micrometric results concerning the duodenum, jejunum and ileum, it can be concluded that the normal values of the studied parameters are a key factor for the integrity of the small intestine in Stara Zagora White turkey, and are dependent on diet conditions and animal husbandry. This thesis complements the view (8) in ducks on the relationship between intestinal mucosal integrity and the environment.

The histological structures of the small intestine in the studied birds include highly differentiated epithelial cells that participate in the formation of the mucous layer. This theory adds the published data $(10,11)$ on the microscopic anatomy of the digestive system in other poultry species.

The data for the histological structure of the intestinal wall in the Stara Zagora White Turkey showed that all three intestinal segments have characteristics specific to the tubular digestive organs. This thesis is confirmed by the histological findings - the presence of tunica mucosa, composed of epithelial cells located on layers of loose fibrous connective and muscle tissue, tunica submucosa, tunica muscularis and tunica serosa. The theory presented by us corresponds to the findings (12) on the histological structure of the small intestine in the Bronze turkey.

The histometric study investigated the patterns in the change in the height of the intestinal villi and the depth of the intestinal crypts in age aspect. It was found that the height of the villi intestinales in the three segments of the small intestine increased with age. These changes were more intense in the jejunum than in the duodenum and ileum. It is important to note the fact that the area of the villi changed in age more noticeably in the jejunum and ileum than in the duodenum. The results of the study convincingly showed that the changes in the depth of the crypts were more intense in the jejunum and ileum than in the duodenum. The presented facts differ from the data (12) that this index changes most intensively in the duodenum in the Bronze turkey.

The presented results differ from the hypothesis (12) for the small intestine in the Bronze turkey, because the height of the intestinal epithelium increased most intensively in the mucosa of the jejunum, while the thickness of the jejunal mucosa 
increased the most during this period, compared to the mucosa of the duodenum and ileum. In addition, tunica submucosa and the sublayers of tunica muscularis grew at almost uniform rates in the three segments of the small intestine, except for the outer sublayer of tunica muscularis in the ileum, where the thickness doubled. Thus the theory (12) on the biological significance of these histometric indicators is complemented.

\section{DECLARATIONS}

\section{Ethics Approval}

This study was approved by the committee for animal ethics in Trakia University (No: 01/2011, No: 09/2016), Bulgaria.

\section{Conflict of Interest}

The authors declare that they have no competing interests.

\section{Author Contribution}

All authors contributed to every step of the article.

\section{Data Availability}

The data that support the findings of this study are available from the corresponding author upon reasonable request.

\section{REFERENCES}

1. Działa-Szczepańczyk E. Asymetria jelit slepych krzyżówki Anas platyrhynchos. Asymmetry of caeca Mallard Anas platyrhynchos. Fol Univ Agr Stet. 2002; 227: 49-54.

2. Działa-Szczepańczyk E. Charakterystyka morfometryczna jelit slepych kaczki domowej rasy Pekin Anas platyrhynchos f. domestica. Morphometric characterisctic of caeca in the Pekin domestic duck Anas platyrhynchos f. domestica. Scientific Fascicles Breeding Review Polish Zoological Society. 2003; 68: 20-27.

3. Działa-Szczepańczyk E, Betlejewska K. Morfologia i morfometria jelit slepych markaczki Melanitta nigra [Morphology and morphometry of caeca in the Black Scoter Melanitta nigra]. Electronic Jurnal of Polish Agricultural Universities seria Biology (www.ejpau.media.pl). 2003; 6/2.

4. Mihailov R. Comparative studies on the morphological features of the digestive tract in Japanese (Coturnix Japonica T. \& Sch.) and Wild quail (Coturnix coturnix L.). Dissertation, Trakia University, Stara Zagora, Bulgaria, 2006.

5. Działa-Szczepańczyk E, Wesołowska I. Morphometric Characteristics of Esophagus And Intestine In Tufted Ducks Aythya Fuligula Wintering On The Baltic Coastal Areas In North-Western Poland. Electronic Journal of Polish Agricultural Universities. 2008; 11: 4.

6. Liu Y, Qiu X, Yu T, Tao J, Cheng Z. How does a woodpecker work? An impact dynamics approach. Acta Mechanica Sinica, 2015; 31: 181-190.

7. Kasperska D, Kokoszyński D, Korytkowska H, Mistrzak M. Effect of age and sex on digestive tract morphometry of guinea fowl (Numida meleagris L.). Folia Biologica. 2012; 60: 45-49.
8. Goudie R, Ryan P. Diets and Morphology of digestive organs in five species of sea ducks wintering in Newfoundland. Journal Yamashina Institute of Ornithology. 1991; 22: 1-8.

9. Gille U, Salomon F, Ronnert J. Growth of the digestive organs in ducks with considerations on their growth in birds in general. British Poultry Science. 1999; 40: 194-202.

10. Andrew W, Hickman C. Digestive systems, In: Andrew W, Hickman C, editors. Histology of the vertebrates, A comparative text. Saint Louis: The C. V. Mosby Company; 1974. p. 243-296.

11. Dibner J, Richards J, Kitchell M, Quiroz M. Metabolic challenges and early bone development. Journal of Applied Poultry Research. 2007; 16: 126-137.

12 Yovchev, D. Histological, histometric and histochemical investigation of the small intestine in the bronze turkey (Meleagris Meleagris gallopavo). Dissertation. Trakia University, Stara Zagora, Bulgaria, 2021.

13. StatView ${ }^{\text {TM }}$ v.4.53 for Windows (Abacus Concepts, Inc). Descriptive statistic. MacWeek, Morgenstem, David, Copyright ${ }^{\circledR}$ 1988. Mac Publishing, Michigan, USA, 1995.

14. Nomina Histologica Veterinaria. http://www.wavaamav.org/downloads/NHV_2017.pdf (10 February 2020 date last accessed), 2017. 